\title{
Cutaneous drug reactions in children: a multicentric study
} \author{
Ömer Çalka \\ ${ }^{1}$ Dermatology Department, Recep Tayyip Erdoğan University Medical Faculty Hospital, Rize, Turkey \\ Head of the Department: Yunus Saral \\ ${ }^{2}$ Dermatology Department, Van Research and Training Hospital, Van, Turkey \\ Head of the Department: Ömer Çalka \\ ${ }^{3}$ Dermatology Department, Atatürk Research and Training Hospital, Ankara, Turkey \\ Head of the Department: Ahmet Metin \\ ${ }^{4}$ Microbiology Department, Recep Tayyip Erdoğan University Medical Faculty Hospital, Rize, Turkey \\ Head of the Department: Osman Birol Özgümüş
}

Nursel Dilek ${ }^{1}$, Hatice Uce Özkol ${ }^{2}$, Ayse Akbaş3 ${ }^{3}$ Fadime Kılınç3, Aziz Ramazan Dilek ${ }^{4}$, Yunus Saral ${ }^{1}$, Ahmet Metin ${ }^{3}$,

Postep Derm Alergol 2014; XXXI, 6: 368-371 DOI: 10.5114/pdia.2014.43881

\begin{abstract}
Introduction: According to studies conducted in outpatients, it is estimated that $2.5 \%$ of children who are treated with a drug will experience a cutaneous adverse drug reaction (CADR).

Aim: To analyze the CADR reports involving pediatric patients recorded by three different university hospitals for describing common, serious, and interesting cutaneous drug eruption patterns.

Material and methods: For this purpose, the patients' data from three different universities were reviewed retrospectively. Diagnosis was based on history, clinical findings and laboratory test results. The CADRs were classified into seven categories; urticaria, angioedema, maculopapular eruption, fixed drug eruption, erythema multiforme, acute generalized exanthematous pustulosis, drug rash with eosinophilia and systemic symptoms syndrome.

Results: A total of 122 patients who had CADRs were enrolled in the study. The most frequently detected cutaneous drug reactions were urticaria + angioedema. Most of patients had no previous experience with the same drug and the most common causative agent of CADRs was antimicrobials.

Conclusions: Since CADRs are relatively rare, the current multicentric study can provide meaningful information about the cutaneous eruption patterns of commonly used drugs.
\end{abstract}

Key words: drug, allergy, cutaneous, children.

\section{Introduction}

Adverse drug reaction (ADR) is defined by the World Health Organization (WHO) as a response to a medicine which is noxious and unintended, and which occurs at doses normally used in a man [1]. Cutaneous adverse drug reaction (CADR) may be defined as an undesirable manifestation of the skin resulting from administration of a particular drug and CADRs are a commonly reported type of ADRs [2, 3]. The incidence of ADRs in hospitalized pediatric patients is $9.53 \%$ [4]. However drug metabolism differs in young children and information on efficacy and toxic effects of drugs is rarely available [5]. The correlation between drug use in children and incidence of ADRs has been a matter of growing awareness in several recent studies [4]. Another important issue with ADRs is that drug eruptions, which are a frequent diagnostic problem for the clinician in an outpatient clinic, commonly have to be differentiated from a viral exanthema [2].

\section{Aim}

In this study, we present the analysis of CADR reports involving pediatric patients (16 years or younger) recorded by three different university hospitals for describing common, serious, and interesting cutaneous drug eruption patterns in a practical manner.

\section{Material and methods}

The present study was approved by the Ethics Committee of the Medical Faculty of Recep Tayyip Erdoğan University. The patients' data from three different universities were reviewed retrospectively. Patients in whom

Address for correspondence: Nursel Dilek MD, Dermatology Department, Recep Tayyip Erdoğan University Medical Faculty Hospital, 53000 Rize, Turkey, phone: 464 2130493, e-mail: nur.dilek@hotmail.com Received: 6.05.2014, accepted: 6.06.2014. 
no medication was given, older than 16 years old and patients with eruption compatible with a viral exanthem were excluded from the study. The data, collected from the subjects were age, sex, implicated drugs, indication of use, time of onset, morphology, type of skin eruption, distribution and duration of the rash, previous experience with the drug, presence of interacting diseases, other drugs or clinical conditions (i.e. infections, cancer, asthma, concomitant drugs, food or drug allergies) and laboratory test results. Diagnosis was based on history, clinical findings and laboratory test results (including complete blood count, serum IgE levels, skin tests and biopsy if needed). In a review of clinical history, the criteria reported by Naranjo et al. were taken into account in causality assessments of drugs [3]. The CADRs were classified into 7 categories: urticaria, angioedema, maculopapular eruption, fixed drug eruption, erythema multiforme, acute generalized exanthematous pustulosis (AGEP), drug rash with eosinophilia and systemic symptoms syndrome (DRESS).

\section{Results}

After applying the exclusion criteria, a total of $122 \mathrm{pa}$ tients (aged 16 years and under) who had CADRs were enrolled the study. Of the 122 patients, 52 were female and 70 were male. The age of patients ranged between 1 and 16 years (mean age: $1.99 \pm 0.76$ (standard deviation)). The most frequently detected cutaneous drug reactions were urticaria + angioedema (51.6\%), maculopapular drug eruptions (30.3\%) and erythema multiforme (5.7\%) (Figure 1).

An important finding of our study is that the most of patients had no previous experience and only 21 patients had a family history. Seventeen patients were diagnosed

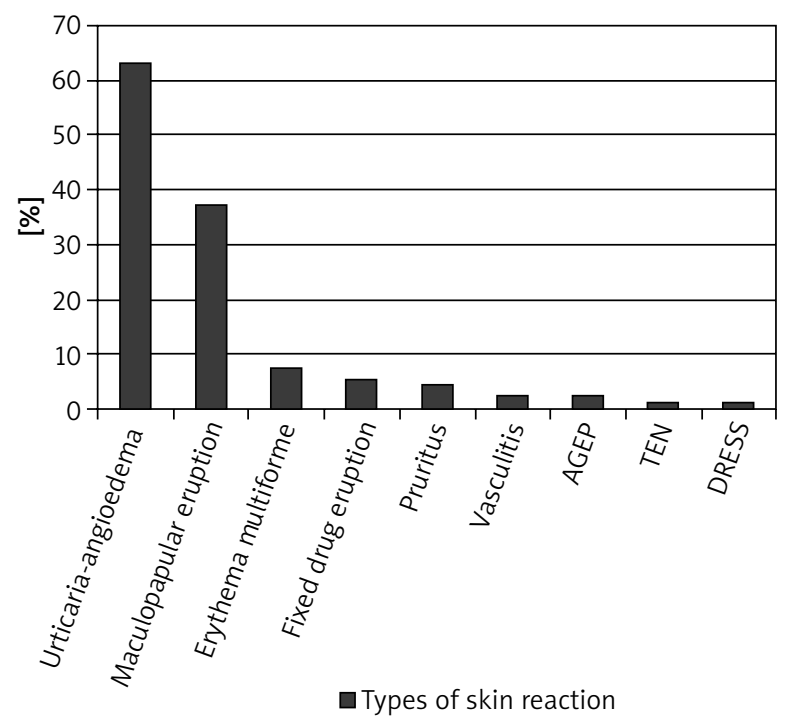

Figure 1. Types of cutaneous drug reactions by biopsy; most of these patients had DRESS and AGEP. Most of the patients were treated as outpatients (90 patients). Table 1 shows the demographic and clinical data of all patients.

According to our study, urticaria, angioedema, and maculopapular eruption was the most common forms of CADRs and the most common causative agent of CADRs was antimicrobials, analgesic, anti-inflammatory and antipyretic drugs. Table 2 shows forms of cutaneous adverse drug reactions and causative agents.

\section{Discussion}

According to studies conducted in outpatients, it is estimated that $2.5 \%$ of children who are treated with a drug, and up to $12 \%$ of children treated with an antibiotic will experience a CADR [3]. Considering the age-related problems of children in drug metabolism (relative liver size, liver blood flow, extent of protein binding and the maturation of drug metabolizing enzymes), the above figures are really worrying $[6,7]$. Drug allergy not only affects the patient's quality of life, it may also lead to delayed treatment, use of suboptimal alternative medications, unnecessary investigations and even death [8]. The skin is the organ most frequently and prominently affected by drug-induced allergic reactions and various genetic and environmental factors may predispose to these allergic reactions and at least 29 drug-related cutaneous reaction patterns have been reported [3, 8-10]. Drug hypersensitivity reactions can be classified as immediate (occur within $1 \mathrm{~h}$ ) or non-immediate (more than $1 \mathrm{~h}$ ) according to the time interval between the last drug administration and onset. Type-I (IgE-mediated) and type-IV (T cell-mediated) pathogenic mechanisms are involved in most immediate and non-immediate reactions, respectively. Usually immediate reactions are manifested clinically by urticaria, angioedema, rhinitis, bronchospasm, and anaphylactic shock, non-immediate reactions manifested by maculopapular rashes. But the later studies have shown that these reactions seem to

Table 1. Demographic and clinical data of all patients

\begin{tabular}{|c|c|}
\hline Variable & Result \\
\hline Gender & 52 females, 70 males \\
\hline Age, mean $\pm S D$ & $1.99 \pm 0.76$ \\
\hline $\begin{array}{l}\text { Previous adverse drug } \\
\text { reaction history with the } \\
\text { same drug }\end{array}$ & 4 patients \\
\hline $\begin{array}{l}\text { Previous adverse drug } \\
\text { reaction history with } \\
\text { different drugs }\end{array}$ & 10 patients \\
\hline Family history & 21 \\
\hline Number of biopsies & 17 \\
\hline Place of treatment & 90 (outpatients), 32 (hospital) \\
\hline
\end{tabular}


Table 2. Forms of cutaneous adverse drug reactions and causative agents

\begin{tabular}{|c|c|c|c|c|c|c|c|c|c|}
\hline \multirow[t]{2}{*}{ Drugs } & \multicolumn{9}{|c|}{ Adverse drug reaction } \\
\hline & UAO & MPE & Pruritus & FDE & Vasculitis & EM & AGEP & TEN & DRESS \\
\hline \multicolumn{10}{|l|}{ Antibiotics $(n=56)$ : } \\
\hline Penicillin and its derivatives & 23 & 11 & & & & 2 & & & \\
\hline Cephalosporins & 3 & 1 & & 1 & & & 1 & & \\
\hline Quinolones & & 2 & & & & & & & \\
\hline Macrolides & 2 & & & & & 2 & & & \\
\hline Teicoplanin & 1 & & & & & & & & \\
\hline Metronidazole & 1 & 1 & & & 1 & & & & \\
\hline Trimethoprim-sulfamethoxazole & & 1 & & & & 3 & 1 & & \\
\hline \multicolumn{10}{|l|}{ AAA $(n=28)$ : } \\
\hline Acetaminophen & 12 & 2 & & & & & & & \\
\hline Metamizole & 2 & & & & & & & & \\
\hline Ibuprofen & 3 & 2 & & 3 & 1 & & & & \\
\hline Scopolamine butyl bromide & 1 & & & & & & & & \\
\hline Indomethacin & 1 & & & & & & & & \\
\hline Naproxen & 1 & & & & & & & & \\
\hline \multicolumn{10}{|l|}{ Vitamins and minerals $(n=9)$ : } \\
\hline Iron & 1 & & & & & & & & \\
\hline Iron and zinc & & 1 & 1 & 1 & & & & & \\
\hline Zinc & 1 & 1 & & & & & & & \\
\hline Multivitamins & & 2 & 1 & & & & & & \\
\hline \multicolumn{10}{|l|}{ Anticonvulsants and antipsychotics $(n=7)$ : } \\
\hline Valproic acid & 1 & 3 & & & & & & & 1 \\
\hline Oxcarbazepine & & 1 & & & & & & & \\
\hline Risperidone & 1 & & & & & & & & \\
\hline \multicolumn{10}{|l|}{ Vaccines $(n=6)$ : } \\
\hline Influenza vaccine & 4 & & 2 & & & & & & \\
\hline \multicolumn{10}{|l|}{ Others $(n=16)$ : } \\
\hline Radiocontrast agent & & 1 & & & & & & 1 & \\
\hline $\begin{array}{l}\text { Antitussive } \\
\text { (Dextromethorphan + Pseudoephedrine + } \\
\text { Chlorpheniramine) }\end{array}$ & 3 & 3 & & & & & & & \\
\hline Immune modulator ( $\beta$-glucan) & 2 & 5 & & & & & & & \\
\hline Laxatives (Lactulose) & 1 & & & & & & & & \\
\hline Total $(n=122)$ & 63 & 37 & 4 & 5 & 2 & 7 & 2 & 1 & 1 \\
\hline
\end{tabular}

UAO - urticaria-angioedema, MPE - maculopapular eruption, FDE - fixed drug eruption, EM - erythema multiforme, AGEP - acute generalized exanthematous pustulosis, TEN - toxic epidermal necrolysis, DRESS - drug rash with eosinophilia and systemic symptoms, AAA - analgesic, anti-inflammatory and antipyretic drugs

be heterogeneous in the pathogenesis of CADRs [11]. Five types constitute the vast majority of cutaneous drug eruptions in children. These types are exanthems, fixed drug reactions, urticarial eruptions, serum sickness-like reactions (SSLR), and photosensitive eruptions [12]. Urticaria-angioedema is the most common form of CADRs in our study and mostly caused by antibiotics and analgesic, anti-inflammatory and antipyretic drugs (AAA). Determination of the connection between the drug and cutaneous reactions is very important as infections are associated with the majority of episodes of acute urticaria [3]. This can only be possible with a correct evaluation 
of clinical history, clinical and laboratory findings. The decline of lesions after discontinuation of treatment with a suspicious drug may provide an important contribution to efforts in this regard as in our study. While maculopapular eruptions (MPE) are the most frequent pattern of cutaneous drug reactions in other studies, in our study MPEs are the second most common form of CADRs and antimicrobials were the most commonly implicated drug [2]. The MPEs are characterized by raised, spotted lesions and originate on the trunk, and eventually spread to the limbs and similar clinical entities may be induced by viruses and immunological mechanisms $[8,13]$. In fact, some of our patients (7 patients with maculopapular eruption) had been diagnosed with viral eruption in different centers, therefore discrimination of both entities is very important. In addition to laboratory findings, this information may be useful when making discrimination; viral infections are generally followed by immunological protection, but in drug reactions re-exposure can induce the reaction again [13].

It is reported in the publications that the risk of severe CADRs ranges between 1 in 1000 and 1 in 10 000, depending on the kind of reaction and the culprit drug [3]. Severe cutaneous reactions such as AGEP, toxic epidermal necrolysis (TEN) and DRESS were rarely encountered in our study (only 4 cases).

In analysis of drugs which cause CADRs, antibiotics were the most common cause of ADRs (45.9\%) as in other studies, followed by AAA (22.9\%), vitamins and minerals (7.3\%), anticonvulsants and antipsychotics (5.7\%) $[9,14,15]$.

A limitation of our study is that impairment of socio-cultural levels in some patients was hampered by receiving the right clinical history. This situation has created problems especially in learning about previous adverse drug reactions (drug name, type of lesion and so on).

\section{Conclusions}

Since CADRs are relatively rare, multicentric studies are required to obtain more data despite some problems in interpretation of data. The current multicentric study is the first comprehensive study on children in our country and provides meaningful information about the cutaneous eruption patterns of commonly used drugs. The authors would like to draw attention that physicians should keep in mind the drug eruption in the differential diagnosis of cutaneous eruption.

\section{References}

1. Thong BY, Tan TC. Epidemiology and risk factors for drug allergy. Br J Clin Pharmacol 2011; 71: 684-700.

2. Rallis E, Balatsouras DG, Kouskoukis C, et al. Drug eruptions in children with ENT infections. Int J Pediatr Otorhinolaryngol 2006; 70: 53-7.
3. Segal AR, Doherty KM, Leggott J, Zlotoff B. Cutaneous reactions to drugs in children. Pediatrics 2007; 120: 1082-96.

4. Dos Santos DB, Coelho HL. Adverse drug reactions in hospitalized children in Fortaleza, Brazil. Pharmacoepidemiol Drug Saf 2006; 15: 635-40.

5. Menniti-Ippolito G, Raschetti R, Da Cas R, et al. Active monitoring of adverse drug reactions in children. Italian Paediatric Pharmacosurveillance Multicenter Group. Lancet 2000; 355: 1613-4.

6. Hines RN. Developmental expression of drug metabolizing enzymes: impact on disposition in neonates and young children. Int J Pharm 2013; 452: 3-7.

7. Johnson TN. The development of drug metabolising enzymes and their influence on the susceptibility to adverse drug reactions in children. Toxicology 2003; 192: 37-48.

8. Warrington R, Silviu-Dan F. Drug allergy. Allergy Asthma Clin Immunol 2011; 7 Suppl. 1: S10.

9. Morales-Olivas FJ, Martínez-Mir I, Ferrer JM, et al. Adverse drug reactions in children reported by means of the yellow card in Spain. J Clin Epidemiol 2000; 53: 1076-80.

10. Szczawińska-Popłonyk A, Bręborowicz A. Vitamin D impact on immune functions: implications for preventive strategy of allergic disease? Postep Derm Alergol 2012; 29: 176-81.

11. Romano A, Torres MJ, Castells M, et al. Diagnosis and management of drug hypersensitivity reactions. J Allergy Clin Immunol 2011; 127 (3 Suppl.): 67-73.

12. Shin HT, Chang MW. Drug eruptions in children. Curr Probl Pediatr 2001; 31: 207-34.

13. Torres MJ, Corzo JL, Leyva L, et al. Differences in the immunological responses in drug- and virus-induced cutaneous reactions in children. Blood Cells Mol Dis 2003; 30: 124-31.

14. Castro-Pastrana LI, Ghannadan R, Rieder MJ, et al. Cutaneous adverse drug reactions in children: an analysis of reports from the Canadian Pharmacogenomics Network for Drug Safety (CPNDS). J Popul Ther Clin Pharmacol 2011; 18: 106-20.

15. Martínez-Mir I, García-López M, Palop V, et al. A prospective study of adverse drug reactions in hospitalized children. $\mathrm{Br}$ J Clin Pharmacol 1999; 47: 681-8. 